\title{
No medicine without psychology: the key role of psychological contribution in clinical settings
}

\section{Gianluca Castelnuovo ${ }^{1,2 *}$ \\ Department of Psychology, Catholic University of Milan, Milan, Italy \\ 2 Istituto Auxologico Italiano IRCCS, Psychology Research Laboratory, Ospedale San Giuseppe, Verbania, Italy \\ *Correspondence: gianluca.castelnuovo@unicatt.it}

Already in the 1945 great expectations about Clinical Psychology were announced in the scientific community: "Never before in history have the applications of psychological science been in such demand as in a war-torn world ... World War II has raised psychiatry, and to a lesser degree psychology, to the status of major reservation by the older "pure" sciences ... Increasingly vociferous demands are being heard from all quarters for a rapprochement of all the psychological sciences to cooperate harmoniously in a unified attack upon the problem of healthy human living ... Clinical psychology has recognized and accepted the challenge." (The field of clinical psychology, 1945, p. 1).

But after this so magnificent beginning, Clinical Psychology experienced profound difficulty maintaining a specific role in the field: "The contents of clinical psychology training programs and the professional practices ... have become so diverse ad extensive that the term clinical psychology may be losing its denominative value ... Thus, if clinical psychology is not in danger of extinction, its contours have become so blurred and its boundaries so permeable that, while the name remains, the coherence and distinctiveness that one inhered in that name have largely disappeared" (Levy, 1984, pp. 486-494).

Despite these past challenges, nowadays Clinical Psychology has found a lot of different applications, with interventions such as psychological assessment, psychological support, psychotherapy, counseling, rehabilitation psychology, neuropsychology, etc. in traditional clinical settings (public and private hospitals, clinics, services, laboratories, etc.) and innovative clinical settings (remote outpatients' clinics, tele-health and e-health based settings). Already in 1956, TIME magazine (Dec. 24, 1956) noted, somewhat provocatively, that medicine alone would be "a soul without psychology" and so today there is no medical area without a corresponding field in Clinical Psychology: psycho-cardiology, psycho-oncology, psycho-geriatrics are only three examples of this significative spread of psychology into clinical settings that were previously traditionally limited to bio-medical intervention.

Clinical Psychology has also received important recognition in terms of its right and need to be correctly implemented and funded: "In Promoting Health: Intervention Strategies from Social and Behavioral Research (Smedley and Syme, 2000), the IOM - Institute of Medicine - focused in depth upon promising areas of social science and behavioral research that would improve the public's health: the vast majority of the nation's health research resources have traditionally been directed toward biomedical research endeavors with less than $5 \%$ of the approximately $\$ 1$ trillion spent annually on health care in the nation being devoted to reducing risks posed by preventable conditions. By itself, however, biomedical research cannot address the most significant challenges to improving the public's health in the new century. Behavioral and social interventions offer great promise to reduce disease morbidity and mortality, but as yet their potential has been relatively poorly tapped" (DeLeon et al., 2003, p. 557).

In order to better exploit its latent power, Clinical Psychology has to forge a more fruitful alliance with Medicine, "accompanying" it in all the clinical acts and adopting a scientific stance. Guidelines, protocols, investigations using an Evidence-Based approach are requested in all the psychological areas related to the treatment of main organic and mental diseases: more space has to be dedicated to Evidence-Based Practice in Clinical Psychology and Empirically Supported Psychological Treatments.

Thus, after the Lancet warning "No health without mental health" (Prince et al., 2007), a new message is needed: "No medicine without psychology".

\section{REFERENCES}

DeLeon, P. H., Hagglund, K. J., Ragusea, S. A., and Sammons, M. T. (2003). Expanding roles for psychologists in the Twenty-First Century. In Handbook of Psychology: Clinical Psychology, Vol. 8, G. Stricker and T. A. Widiger, eds (Hoboken, NJ, John Wiley \& Sons), pp. 551-568.

Levy, L. H. (1984). The metamorphosis of clinical psychology. Toward a new charter as human services psychology. Am. Psychol. 39, 486-494.

Prince, M., Patel, V., Saxena, S., Maj, M., Maselko, J., Phillips, M. R., and Rahman, A. (2007). No health without mental health. The Lancet 370, 859-877.

Smedley, B. D., and Syme, S. L. (eds) (2000). Promoting Health: Intervention Strategies from Social and Behavioral Research. Washington, DC, National Academy Press.

The field of clinical psychology (1945). J. Clin. Psychol. $1,1-20$.

Received: 09 February 2010; accepted: 18 February 2010; published online: 17 March 2010.

Citation: Castelnuovo G (2010) No medicine without psychology: the key role of psychological contribution in clinical settings. Front. Psychology 1:4. doi: 10.3389/ fpsyg.2010.00004

This article was submitted to Frontiers in Psychology for Clinical Settings a specialty of Frontiers in Psychology. Copyright (c) 2010 Castelnuovo. This is an open-access article subject to an exclusive license agreement between the authors and the Frontiers Research Foundation, which permits unrestricted use, distribution, and reproduction in any medium, provided the original authors and source are credited. 